\title{
Water Wave Optimization Algorithm for Solving Multi-Area Economic Dispatch Problem
}

\author{
L. Lakshminarasimman \\ Department of Electrical \\ Engineering \\ Annamalai University \\ Annamalainagar, \\ Chidambaram 608002
}

\author{
M. Siva \\ Department of Electrical \\ Engineering \\ Annamalai University \\ Annamalainagar, \\ Chidambaram 608002
}

\author{
R. Balamurugan \\ Department of Electrical \\ Engineering \\ Annamalai University \\ Annamalainagar, \\ Chidambaram 608002
}

\begin{abstract}
This paper presents the Water Wave Optimization Algorithm (WWOA) for solving multi-area economic dispatch (MAED) problem with tie line constraints considering transmission losses, area demand constraints, multiple fuels options, valvepoint loading effects and prohibited operating zones. Here, the amount of power that can be economically generated in one or more areas are exchanged with other areas with deficient generation through the interconnected tie-lines while meeting out the area wise and total power demand and other constraints is formulated as the MAED problem. WWOA is one of the nature inspired algorithm which mimics the phenomena of water waves for global optimization is implemented for the solution of multi-area economic dispatch problem. The effectiveness of the proposed algorithm has been verified on three different test systems and are compared with Teaching learning based optimization (TLBO), differential evolution (DE), evolutionary programming (EP) and real coded genetic algorithm (RCGA), considering the quality of the solution obtained, and the results shows a quick convergence of the proposed algorithm and are found to be superior than the other methods in the literature and seems to be a potential alternative advancement in practical power system for solving the MAED problems.
\end{abstract}

\section{Keywords}

Water wave optimization algorithm, multi-area economic dispatch, multiple fuel options, cost minimization, prohibited operating zones.

\section{INTRODUCTION}

Economic dispatch (ED) is one of the main optimization problems in power system operation [1]. The load demand is allocated among the committed generators by ED most economically, while fulfilling the physical and operational constraints in a single area. As many areas are interconnected, the concept of multi-area power system arrives and they should have their reliability, stability enhanced and also the total production cost to be less when compared to a single area system. Generally, the generators are divided into several generation areas interconnected by the tie-lines. Multi-area economic dispatch (MAED) is an extension of single area economic dispatch which determines the generation level and interchange of power through tie-lines between areas minimizing the total fuel cost in all areas while satisfying the generator inequality constraints, power balance constraints, tie-line capacity constraints and import and export constraints [2]. Multiple fuel options, POZ constraints and valve point loading effects including losses were also considered while solving for MAED problems. The economic dispatch problem is usually solved without considering the transmission tie-line constraints. Some strategies have been reported in literature [2] for solving economic dispatch problems considering import and export constraints between areas. Romano et al. [3] presented the Dantzig-Wolfe decomposition principle to the constrained economic dispatch of multi-area systems. Many conventional optimization techniques like equal incremental cost method [2, 4], lagrangian relaxation approach [5], and decomposition method [6] were demonstrated to solve multi-area economic dispatch (MAED) problem which may be fast and efficient. However, for large MAED problems, the increase of constraints results in excessive computational burden. Stochastic techniques have been developed to reduce the above said burden on the computational time. Artificial intelligence (AI) techniques like GA, PSO, Evolutionary programming (EP) etc. are widely used for resolving many optimization problems. There were also some drawbacks such as in GA the solution space is discrete (binary representation) and hence it cannot be implemented for continuous problems like MAED. Then realcoded GA was proposed for continuous multi-dimensional problem [7, 8]. Modern heuristic algorithms such as Harmony search algorithm (HSA) [9], modified Differential evolution algorithm [10], Cuckoo search algorithm [11], Immune algorithm (IA) [12], Evolutionary programming [13] are tested and reported on various single and multi-area economic dispatch problems. Combined multi-area problem [14] with emission constraint was proposed using chaotic artificial bee colony (CABC) methodology. Although there are more methods available for solving the problem of MAED, the larger the system, greater is the complexity due to various constraints which necessitates developing efficient algorithms to stably find an optimal solution. In this context, the focus of this work is to demonstrate the efficiency of a nature inspired approach for solving MAED problems in a practical power system.

In this paper WWOA has been applied to solve the MAED problem and are validated on three test cases i) a two area four units system ii) a three area ten units system and iii) a four area forty units system while satisfying the real power balance constraint, generator inequality constraints, tie-line power flow constraints considering the multiple fuel options and the valve point loading effects. The performance of the WWOA approach has been compared with popular techniques such as Real Coded Genetic Algorithm (RCGA), Differential Evolution (DE), Evolutionary Programming (EP) and Teacher-Learning Based Algorithm (TLBO) which are reported in [17]. 


\section{PROBLEM FORMULATION}

The main objective of the MAED problem is to minimize the overall generation fuel cost by determining the generation levels for supplying the loads to all areas while satisfying the power balance constraints, generator inequality constraints and the tie-line capacity constraints. Additionally, constraints like prohibited operating zones and valve point loadings are also considered. In this work three different types of MAED problems have been considered and are detailed in the upcoming sections. Types of MAED problems considered along with tie-line constraints, power balance and power inequality constraints are:-

1. MAED with POZ and transmission losses.

2. MAED with Multiple fuel options, valve point effects and transmission losses.

3. MAED with Multiple fuel options and valve point effects.

\subsection{Multi-Area Economic Dispatch (MAED) Problem}

The objective function $\left(F_{t}\right)$ of MAED problem, which is the total fuel cost of committed generators of all areas without considering valve point loading effects, may be written as,

$$
F_{t}=\sum_{i=1}^{N} \sum_{j=1}^{M_{i}} F_{i j}\left(P_{i j}\right)=\sum_{i=1}^{N} \sum_{j=1}^{M_{i}} a_{i j}+b_{i j} P_{i j}+c_{i j} P_{i j}^{2}
$$

where $F_{i j}\left(P_{i j}\right)$ is the fuel cost function of $j^{\text {th }}$ generator in area $i$ and is usually expressed as a quadratic polynomial. $N$ is the number of areas, $M_{i}$ is the number of generators committed to work in area $i$. The following are the constraints subjected to minimize the objective function.

\subsubsection{Real power balance constraint}

For each area ' $i$ ',

$$
\sum_{j=1}^{M_{i}} P_{i j}=P_{D i}+P_{L i}+\sum_{k, k \neq i} T_{i k} \quad i \in N
$$

The transmission power loss $\left(P_{L i}\right)$ of area ' $i$ ' may be expressed by using B- loss coefficients by Kron's formula as,

$$
P_{L i}=\sum_{l=1}^{M_{i}} \sum_{j=1}^{M_{i}} P_{i j} B_{i l j} P_{i l}+\sum_{j=1}^{M_{i}} B_{0 i j} P_{i j}+B_{00 i}
$$

where $P_{D i}$ is the area ' $i$ ' real power demand; $T_{i k}$ is the tie-line real power transfer from area $i$ to area ' $k$ '. $\left(T_{i k}\right.$ is positive when the power flows from area ' $i$ ' to ' $k$ ' and it is negative when the power flows in the opposite direction). $B_{i l j}, B_{0 i}, B_{00}$ are the $\mathrm{B}$ coefficients.

\subsubsection{Tie-line constraints}

The tie-lines interconnecting the areas are helpful in sharing the power generation in between the interconnected areas in an economical way with some power flow limitations. The tie-line real power transfers $T_{i k}$ from area ' $i$ ' to area ' $k$ ' shall not exceed the tie-line transfer maximum capacity on both directions for the sake of security concern.

$$
-T_{i k}^{\max } \leq T_{i k} \leq T_{i k}^{\max }
$$

where $T_{i k}^{\max }$ is the maximum power flow limit from area ' $i$ ' to area ' $k$ ' and $-T_{i k}^{\max }$ is the maximum power flow limit from area ' $k$ ' to area ' $i$ '. This constraint is necessary for the real power balance constraint and it is shown in equation (2).

\subsubsection{Real power generation capacity constraints}

The generator lower limit $P_{i j}^{\min }$ and the upper limit $P_{i j}^{\max }$ are used to control the real power generated by each generator.

$$
P_{i j}^{\min } \leq P_{i j} \leq P_{i j}^{\max }
$$

where $i \in N$ and $j \in M_{i}$. N is the number of areas, $M_{i}$ is the number of committed generators in area $i$.

\subsubsection{Prohibited operating zones}

The prohibited operating zones are the range of power output of a generator where the operation causes vibrations of the turbine shaft bearing caused by the opening and closing operations of the steam valve, limited machine operations by boilers, feed pumps, etc. The machines or their accessories may get damaged if they are made operate in these prohibited operating regions. Practically, as it is difficult to identify the prohibited operating zones by actual performance testing, the best economic idea is to avoid operation of generators in those prohibited areas. So, this constraint has been added to improve the reality of the economic operation.

$$
\left\{\begin{array}{l}
P_{i, \min } \leq P_{i} \leq P_{i, 1}^{l} \\
P_{i, k-1}^{u} \leq P_{i} \leq P_{i, k}^{l} \\
P_{i, z}^{u} \leq P_{i} \leq P_{i . \max }^{u}
\end{array}\right.
$$

where $p_{i, k}^{l}$ and $p_{i, k}^{u}$ are the lower and upper limits of $k^{\text {th }}$ prohibited zone respectively. $z$ is the number of prohibited operating zones for the $i^{\text {th }}$ generator.

\subsection{MAED with Multiple Fuel Options and Valve Point Effect}

Practically multiple fuel sources are used to feed the generators. In order to depict the fuel type changes, each generator variable is represented with several piecewise quadratic functions superimposed with sine terms and the most economical fuel to burn has to identified by the generator from the options available.

As each steam valve starts to open, they produce a rippling effect on the unit curve characteristics and this effect is added to the objective function as sinusoidal function. The fuel cost objective function considering the valve point loading effects is given by,

$$
\begin{aligned}
& F_{t}=\sum_{i=1}^{N} \sum_{j=1}^{M_{i}} F_{i j}\left(P_{i j}\right) \\
&=\sum_{i=1}^{N} \sum_{j=1}^{M_{i}} a_{i j}+b_{i j} P_{i j}+c_{i j} P_{i j}^{2} \\
&+\left|d_{i j} \times \sin \left\{e_{i j} \times\left(P_{i j}^{\min }-P_{i j}\right)\right\}\right|
\end{aligned}
$$

The fuel cost function $\left(\mathrm{F}_{\mathrm{t}}\right)$ of the $\mathrm{i}^{\text {th }}$ generator with $\mathrm{N}_{\mathrm{F}}$ fuel types considering valve point loading is expressed as

$$
\begin{aligned}
& F_{t}=\sum_{i=1}^{N} \sum_{j=1}^{M_{i}} F_{i j}\left(P_{i j}\right) \\
& =\sum_{i=1}^{N} \sum_{j=1}^{M_{i}} a_{i j m}+b_{i j} P_{i j}+c_{i j m} P_{i j}^{2} \\
& +\mid d_{i j m} \\
& \quad \times \sin \left\{e_{i j m} \times\left(P_{i j m}^{\min }-P_{i j}\right)\right\} \mid \\
& \text { if } \quad P_{i j m}^{\text {min }} \leq P_{i j} \leq P_{i j m}^{\max }
\end{aligned}
$$

for fuel type ' $\mathrm{m}$ ' and $\mathrm{m}=1,2, \ldots, \mathrm{N}_{\mathrm{F}}$ 


\subsubsection{Determination of generation level of} dependent generator

The committed generators $M_{i}$ in area $i$ deliver their power output subject to the power balance constraint, tie line capacity constraints and the respective generation capacity constraints. Assuming the power loading of first $\left(M_{i}-1\right)$ generators are known, the power level of the $M_{i}^{\text {th }}$ generator (i.e. the dependent generator) as rearranged from eq. (3) is given by

$$
P_{i M_{i}}=P_{D i}+P_{L i}+\sum_{k, k \neq i} T_{i k}-\sum_{j=1}^{M_{i}-1} P_{i j}
$$

The transmission loss $P_{L i}$ is a function of all generator outputs including the dependent generator and it is given by

$$
\begin{aligned}
P_{L i}=\left[\sum_{l=1}^{M_{i}-1} \sum_{j=1}^{M_{i}-1}\left(P_{i j} B_{i l j} P_{i l}\right)+2 P_{i M_{i}}\left(\sum_{j=1}^{M_{i}-1} B_{i M j} P_{i j}\right)\right. \\
+B_{i M_{i} M_{i} P_{i M_{i}}^{2}} M^{M_{i}-1} \\
\left.+\sum_{j=1}\left(B_{0 i j} P_{i j}\right)+B_{0 i M_{i}} P_{i M_{i}}+B_{00 i}\right]
\end{aligned}
$$

On substituting eq. (9) in eq.(8), expanding and rearranging, equation (8) becomes,

$$
\begin{aligned}
& B_{i M_{i} M_{i}} P_{i M_{i}}^{2}+\left(2 \sum_{j=1}^{M_{i}-1} B_{i M_{i} j} P_{i j}+B_{0 i M_{i}}-1\right) P_{i M_{i}} \\
&+\left(P_{D i}\right. \\
&+\sum_{k, k \neq i}^{M_{i}-1} T_{i k} \\
&+\sum_{j=1}^{M_{i}-1} \sum_{j=1}^{M_{i}-1} P_{i j} B_{i l j} P_{i l} \\
&\left.+\sum_{j=1}^{M_{0 i j}} B_{i j}-\sum_{j=1}^{M_{i}-1} P_{i j}+B_{o o i}\right)=0
\end{aligned}
$$

The loading of the dependent generator is found by solving the quadratic equation (11) using standard algebraic method.

\section{WATER WAVE OPTIMIZATION ALGORITHM}

\subsection{Inspiration}

Nature has been the main source of inspiration for the majority of the population-based stochastic optimization techniques which performs the optimization randomly. Water wave optimization algorithm is a nature inspired algorithm recently proposed by Zheng [15]. Initially the optimization process is started by creating a set of random solutions. These initial solutions are then combined, moved, or evolved over a predefined number of steps called iterations or generations. This is almost the main framework of all population-based algorithms.

In this paper, the application of Water Wave Optimization Alg orithm (WWOA) is proposed to solve the multi area economic dispatch problems with certain constraints.

\subsection{Mathematical Model of WWOA}

\subsubsection{Propagation}

From the initial wave population, each wave is allowed to propagate only once in each iteration. The propagation operator shifts the original wave $x$ in each dimension to produce a new propagated wave $x^{\prime}$. The new wave is modelled by the following equation:

$$
x^{\prime}(d)=x(d)+r n d(-1,1) \cdot \lambda \cdot L(d)
$$

where $\operatorname{rnd}(-1,1)$ is a uniformly distributed random number within the range $[-1,1]$ and $L(d)$ is the length of the $d t h$ dimension. $\lambda$ is the wavelength of wave $x$, which is updated after each generation, as follows:

$$
\lambda=\lambda \cdot \alpha^{-\left(f(x)-f_{\min }+\epsilon\right) /\left(f_{\max }-f_{\min +\epsilon)}\right.}
$$

where $\alpha$ is the wavelength reduction coefficient, where $f(x)$ is the fitness of the original wave, $f_{\max }$ and $f_{\min }$ are respectively the maximum and minimum fitness values among the current population and $\epsilon$ is a very small positive number to avoid division-by-zero. The equation (13) ensures that the waves with higher fitness value have lower wavelengths and thus propagate with smaller ranges.

\subsubsection{Breaking}

In WWOA, the breaking operation is performed only on a wave $x$ that finds a new best solution (i.e., $x$ becomes the new $x^{*}$ ) and conduct a local search around $x^{*}$ using ' $k$ ' solitary waves to simulate wave breaking using the following equation.

$$
x^{\prime}(d)=x(d)+N(0,1) \cdot \beta \cdot L(d)
$$

where $\beta$ is the breaking coefficient. $N$ is the Gaussian random number, $L(d)$ is the length of the $\mathrm{d}^{\text {th }}$ dimension. If none of the solitary waves are better than $x^{*}, x^{*}$ is retained; otherwise $x^{*}$ is replaced by the fittest one among the solitary waves. Totally $k$ number of solitary waves $x^{\prime}$ are generated at each dimension $d$ and the value of $k$ is generated randomly between 1 and $k_{\max }$. Overall the Breaking process helps in exploitation for a better solution.

\subsubsection{Refraction}

During wave propagation, if the wave path is not perpendicular to the isobaths the wave gets deflected and the wave converges in shallow regions and diverges in deep regions. In WWOA, refraction is performed on the waves whose height decreases to zero. The position of the wave after refraction is calculated as,

$x^{\prime}(d)=N\left(\frac{x^{*}(d)+x(d)}{2}, \frac{\left|x^{*}(d)-x(d)\right|}{2}\right)$

where $N$ is a Gaussian random number, $x^{*}$ is the best solution found so far and $d$ is the dimension of the problem. So the new position of the wave is a random number midway between the original and the current best known position. Once the refraction phase is ended, the wave height of $x^{\prime}$ is reset to its maximum value $h_{\max }$ and its wavelength is set by,

$\lambda^{\prime}=\lambda \frac{f(x)}{f\left(x^{\prime}\right)}$

Overall the Refraction process supports exploration capability of the algorithm. 


\section{Implementation of WWO Algorithm for MAED Problem}

Apart from the population size there are four main parameters which control the WWO Algorithm. They are: maximum wave height $h_{\max }$, wavelength reduction coefficient $\alpha$, breaking coefficient $\beta$, and maximum number of breaking directions $k_{\max }$. In all our test systems the parameters, $\alpha=$ 1.01, $\beta=0.001$, and $h_{\max }=6$ are used for the study of multiarea economic dispatch problems and the maximum number of iterations is considered as the stopping criteria. The following are the parameter selection range as recommended by Zheng [15] in his literature.

\subsection{Initialization}

The initial control parameters such as $\square_{\max }, \alpha, \beta$ are all set with initial values as mentioned above and $k_{\max }=$ $\min (12, D / 2)$ to start with the iterations. Also $N_{p}=(20$ to $100)$, iter_max $=(50$ to 1000$)$ where $N_{p}$ is the number of population. The stopping criterion is the number of iterations. The $k_{\max }$ value selection depends on the dimension (D) of the problem considered.

1. Initialize the population with ' $n$ ' waves with all generators and tie-lines except the dependent generators in each area as follows, as follows

Let the $n^{\text {th }}$ solution of the population is represented

$$
\begin{aligned}
& P_{n} \quad\left[\begin{array}{c}
\left(P_{11}, P_{12}, \ldots, P_{1 M_{1}}\right), \ldots,\left(P_{i 1}, P_{i 2}, \ldots, P_{i M_{i}}\right), \ldots,\left(P_{N 1}, P_{N 2}, \ldots, P_{N M_{N}}\right), \\
\left(T_{12}, T_{13}, \ldots, T_{1 N}\right), \ldots,\left(T_{23}, T_{24}, \ldots, T_{2 N}\right), \ldots,\left(T_{(N-1) N}\right)
\end{array}\right] \\
& \text { where } n=1,2, \ldots, N_{P}
\end{aligned}
$$

The initial population of individuals $P_{n}$ for $\mathrm{n}=1,2, \ldots, N_{p}$ excluding one dependent generator in each area is selected randomly from a feasible range for each independent unit in area $\mathrm{m}$. The elements in the initial solution $P_{n}$ are the real power generations of all the areas and the tie-line real power flows. The real power output $\left(P_{i j}\right)$ of the $j^{\text {th }}$ generator in area $i$ is boundary fixed by $P_{i j} \sim U\left(P_{i j}^{\min }, P_{i j}^{\max }\right)$ where $i=$ $1,2, \ldots N_{p}$ and $j=1,2, \ldots, M_{i}$. Similarly the tie-line power flow is boundary fixed by $T_{i k} \sim U\left(-T_{i k}^{\min }, T_{i k}^{\max }\right)$. Where $U(a, b)$ denotes the uniform random variable ranging over $a$ and $b$. Each vector in the population should satisfy the constraints given in eq. (2), (4), (5) and (6).

1.1. Calculate the area wise power demand by

$$
P_{D i}=P_{D i, r e q}+\sum_{k, k \neq i} T_{i k}
$$

where, $P_{D i, r e q}$ is the required power demand of the area ' $\mathrm{i}$ '.

1.2. Find the values of the dependent generator in each area using eq. (9), (10) and by solving eq. (11).

2. Evaluate the initial fitness $f(x)$ of each wave for the obtained generator values, by using

$f(x)=F_{t}=\frac{1}{\sum_{i=1}^{N} \sum_{j=1}^{M_{i}}\left[F_{i j}\left(P_{i j}\right)\right]}$

3. Select a wave from the initial population with maximum fitness as the best solution wave $\left(x^{*}\right)$

\section{Set iter $=1$.}

While (iter $<=$ iter_max), go to step 4.1. Else, go to step 4.9.
4.1. For each wave $(x)$ in the population, perform Propagation only once in each iteration by eq. (12).

4.2. If $f\left(x^{\prime}\right)>f(x)$ then go to step 4.3. Else, go to step 4.5. 4.3. If $f\left(x^{\prime}\right)>f\left(x^{*}\right)$ then go to step 4.3.1. Else, go to step 4.4.

4.3.1. Perform Breaking on wave $\left(x^{\prime}\right)$ to obtain solitary waves $\left(x_{s}\right)$, Where, $s=1$ to $k_{\max }$ (a random number predefined based on the dimension of the problem).

4.3.2. Compare fitness of the Solitary waves $\left(x_{s}\right), s=$ 1 to $k_{\text {max }}$, with the best wave fitness $f\left(x^{*}\right)$.

i.e., If $\max \left(f\left(x_{s}\right)\right)>f\left(x^{*}\right)$ then

Update $\left(x^{*}\right)$ with best of $\left(x_{s}\right)$.

Else,

Replace $\left(x^{*}\right)$ with $\left(x^{\prime}\right)$.

4.4. Replace $(x)$ with $\left(x^{\prime}\right)$ and go to step 4.8.

4.5. Wave $(x)$ remains the same and decrease the wave height $(x . h)$ by one.

If $(x . h)=0$, then go to step 4.6. Else, go to step 4.7.

4.6. Perform Refraction on wave $(x)$ to a new $\left(x^{\prime}\right)$ based on eq. (15) and (16).

Reset wave height $\left(x^{\prime} . h\right)$ to $h_{\max }$.

4.7. Update the wavelengths $(\lambda)$ of the population using eq. (13)

4.8. Return the best solution wave $\left(x^{*}\right)$ obtained so far. iter $=$ iter +1 , go to step 4.

4.9. Stop and Print the global best results

\section{NUMERICAL SIMULATION RESULTS AND DISCUSSION}

The Water wave optimization algorithm (WWOA) is implemented on three different cases of test systems for computing its performance and optimization capability. Many trials with independent initial population are made to get a valuable conclusion of the performance of the algorithm. In order to attest the effectiveness of the proposed WWO algorithm, it is compared with some of the recent techniques [17] such as real coded genetic algorithm (RCGA), evolutionary programming (EP), differential evolution (DE), and Teaching-Learning based optimization (TLBO).

\section{Test Systems}

Here we present the results of simulations on three test systems to evaluate the performance of Water wave optimization algorithm.

Case 1: Two area six unit small scale system, considering POZ and Losses.

Case 2: Three area ten unit medium scale system including multi-fuel options and valve point effects.

Case 3: Four area forty unit large scale system with valve point effect.

\subsection{Test System 1}

This system consists of two areas with six generating units. Each area consists of three generators with prohibited operating zones. The total demand of the system is $1263 \mathrm{MW}$. Area 1 is shares $60 \%$ of the total demand while area 2 is to maintain the remaining $40 \%$ of the total demand. Network transmission losses and transmission line capacity limits for the areas are also considered. The transmission power flow limit of the system is limited to $100 \mathrm{MW}$. The generator data, cost coefficients, B-loss coefficients and power limits are taken from [18] which are modified from [19]. Table 1 compares the best solution results obtained using RCGA, EP, DE, TLBO and WWOA. The tie-line power flow of 82.77 MW is from area 1 to area 2 and it is seen that the total 
generation fuel cost is well reduced when compared with other results reported presented in literature.

Table 1. Simulation results comparison for Test System 1 ( 2 area 6 units with poz and losses)

\begin{tabular}{|c|c|c|c|c|c|}
\hline $\begin{array}{l}\text { Units } \\
\text { (MW) }\end{array}$ & RCGA & EP & $\mathrm{DE}$ & TLBO & WWOA \\
\hline $\mathrm{P}_{1,1}$ & 500 & 500 & 500 & 500 & 500 \\
\hline$P_{1,2}$ & 200 & 200 & 200 & 200 & 200 \\
\hline$P_{1,3}$ & 149.6328 & 149.9919 & 150 & 150 & 150 \\
\hline $\mathrm{P}_{2,1}$ & 205.9398 & 206.4493 & 204.3341 & 204.3271 & 205.2816 \\
\hline $\mathrm{P}_{2,2}$ & 155.8322 & 154.8892 & 154.7048 & 154.7095 & 154.1240 \\
\hline $\mathrm{P}_{2,3}$ & 65.2209 & 65.2717 & 67.5770 & 67.5795 & 67.0561 \\
\hline $\mathrm{T}_{12}$ & 82.4135 & 82.7652 & 88.7731 & 82.7731 & 82.7731 \\
\hline $\mathrm{P}_{\mathrm{L} 1}$ & 9.4193 & 9.4267 & 9.4269 & 9.4269 & 9.4269 \\
\hline $\mathrm{P}_{\mathrm{L} 2}$ & 4.2064 & 4.1754 & 4.1890 & 4.1892 & 4.0348 \\
\hline $\begin{array}{l}\text { Total } \\
\text { Cost } \\
(\$ / h)\end{array}$ & $12,256.23$ & $12,255.43$ & $12,255.42$ & $12,255.39$ & $12,254.2162$ \\
\hline
\end{tabular}

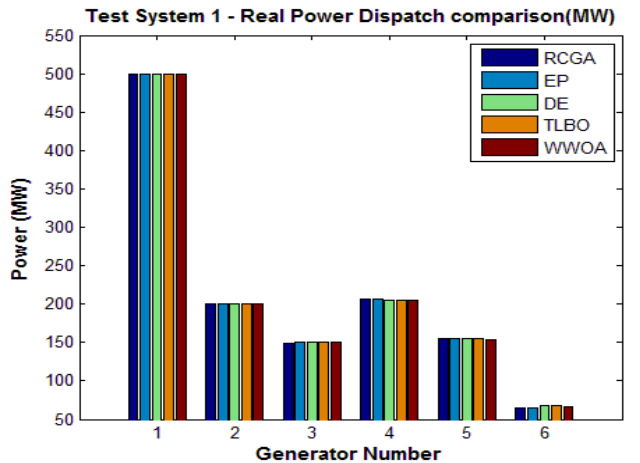

Fig 1: Test System 1 - Power dispatch comparison

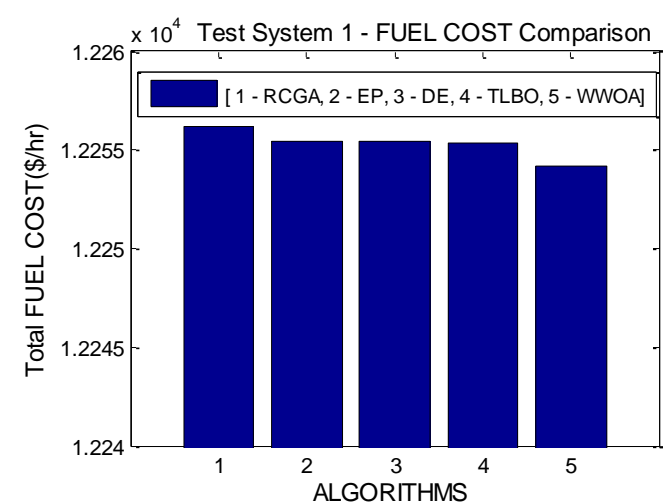

Fig 2: Test System 1 - Fuel cost comparison

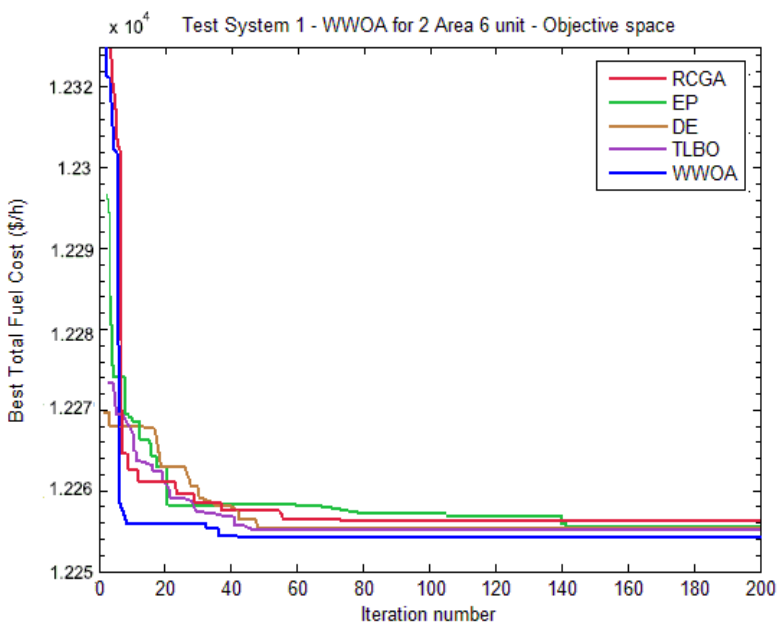

Fig 3: Test System 1 - Fuel cost convergence comparison

Table 2. Simulation results comparison for Test System 2 (3 area 10 units with MFO and valve point loading and losses)

\begin{tabular}{|c|c|c|c|c|c|c|}
\hline $\begin{array}{l}\text { Units } \\
\text { (MW) }\end{array}$ & $\begin{array}{l}\text { Fuel } \\
\text { Type }\end{array}$ & RCGA & $\mathrm{EP}$ & DE & TLBO & WWOA \\
\hline $\mathrm{P}_{1,1}$ & 2 & 239.0958 & 223.8491 & 225.4448 & 224.3088 & 249.6743 \\
\hline $\mathrm{P}_{1,2}$ & 1 & 216.1166 & 209.5759 & 210.1667 & 210.6642 & 211.6655 \\
\hline $\mathrm{P}_{1,3}$ & 2 & 484.1506 & 496.0680 & 491.2844 & 491.6998 & 463.5699 \\
\hline $\mathrm{P}_{1,4}$ & 3 & 240.6228 & 237.9954 & 240.8956 & 240.6247 & 241.1654 \\
\hline $\mathrm{P}_{2,1}$ & 1 & 259.6639 & 259.4299 & 251.0049 & 249.5648 & 252.2675 \\
\hline $\mathrm{P}_{2,2}$ & 3 & 219.9107 & 228.9422 & 238.8603 & 235.8978 & 235.6255 \\
\hline $\mathrm{P}_{2,3}$ & 1 & 254.5140 & 264.1133 & 264.0906 & 263.7414 & 264.9052 \\
\hline $\mathrm{P}_{3,1}$ & 3 & 231.3565 & 238.2280 & 236.9982 & 237.1327 & 244.2385 \\
\hline $\mathrm{P}_{3,2}$ & 1 & 341.9624 & 331.2982 & 326.5394 & 332.5910 & 320.0000 \\
\hline $\mathrm{P}_{3,3}$ & 1 & 248.2782 & 246.6025 & 250.3339 & 249.4628 & 250.9638 \\
\hline \multicolumn{2}{|c|}{$\mathrm{T}_{12}$} & -93.1700 & -100 & -99.4680 & -99.8288 & -99.9871 \\
\hline \multicolumn{2}{|c|}{$\mathrm{T}_{23}$} & -43.7824 & -32.5231 & -30.2810 & -31.2615 & -31.9081 \\
\hline \multicolumn{2}{|c|}{$\mathrm{T}_{31}$} & 93.8739 & 100 & 100 & 99.7334 & 99.8406 \\
\hline \multicolumn{2}{|c|}{$\mathrm{P}_{\mathrm{L} 1}$} & 17.0297 & 17.4884 & 17.2680 & 17.2095 & 15.9028 \\
\hline \multicolumn{2}{|c|}{$\mathrm{P}_{\mathrm{L} 2}$} & 9.7010 & 10.0085 & 9.7688 & 9.8488 & 9.7192 \\
\hline \multicolumn{2}{|c|}{$\mathrm{P}_{\mathrm{L} 3}$} & 8.9408 & 8.6056 & 8.5905 & 8.6037 & 8.4536 \\
\hline \multicolumn{2}{|c|}{ Total Cost $(\$ / \mathrm{h})$} & 657.3325 & 655.1716 & 654.0184 & 653.9977 & 650.9991 \\
\hline
\end{tabular}




\subsection{Test System 2}

This system comprises of three areas with ten generating units. The total load demand is $2700 \mathrm{MW}$. Area 1 includes first 4 units and shares $50 \%$ of the total load demand. The next 6 units are divided equally between area 2 and 3 with each $25 \%$ of total load demand. Here the system considers valve-point loading effects and multi-fuel sources with three fuel options. To obtain the accurate cost model for each generating unit, the valve-point effects must be incorporated into the cost model as a sinusoidal function. Transmission loss for each area is also accounted. The generator data has been taken from [16]. The power flow limit from area 1 to area 2 or from area 2 to area 1 is $100 \mathrm{MW}$. Similarly the power flow limit from area 1 to area 3 or from area 3 to area 1 is 100
MW. Also the power flow limit from area 2 to area 3 or its vice-versa is limited to $100 \mathrm{MW}$. Results obtained from the proposed WWOA, TLBO, DE, EP and RCGA have been presented in Table 2. The population size and the maximum iterations used are 30 and 500 (300) respectively. In order to emphasize the transition of convergence characteristics near initial iterations, the last 200 iterations were chopped for convenience. The comparison of real power generation and the total generation cost have been shown in Fig. 4 and Fig. 5 respectively. The cost convergence characteristic of this test system obtained from WWOA, TLBO, DE, EP and RCGA is shown in Fig. 6 which emphasizes the efficiency of the algorithm in obtaining the best solution.

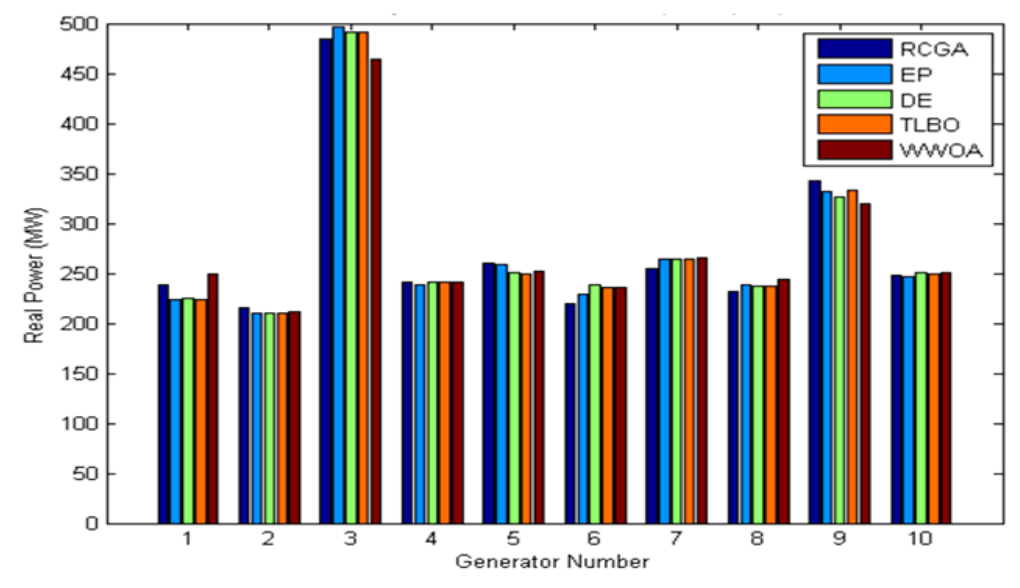

Fig 4: Test System 2 - Power dispatch comparison

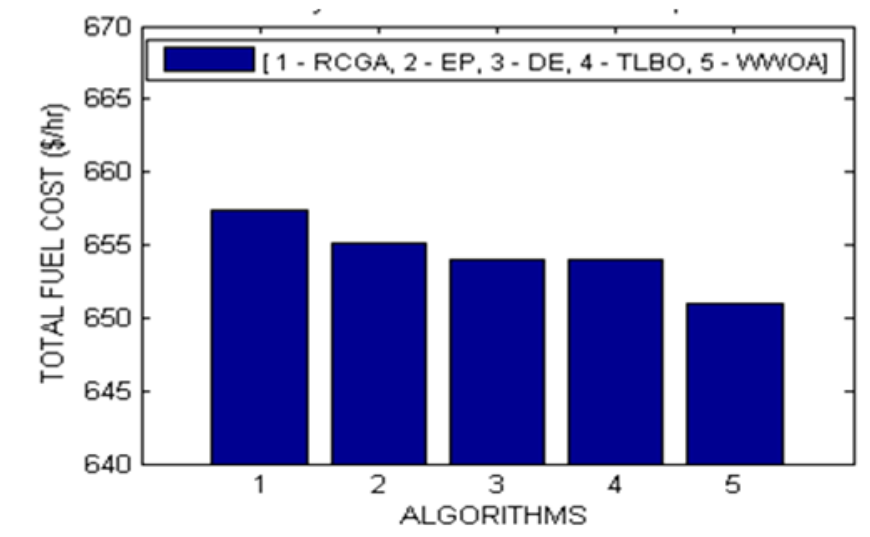

Fig 5: Test System 2 - Fuel cost comparison

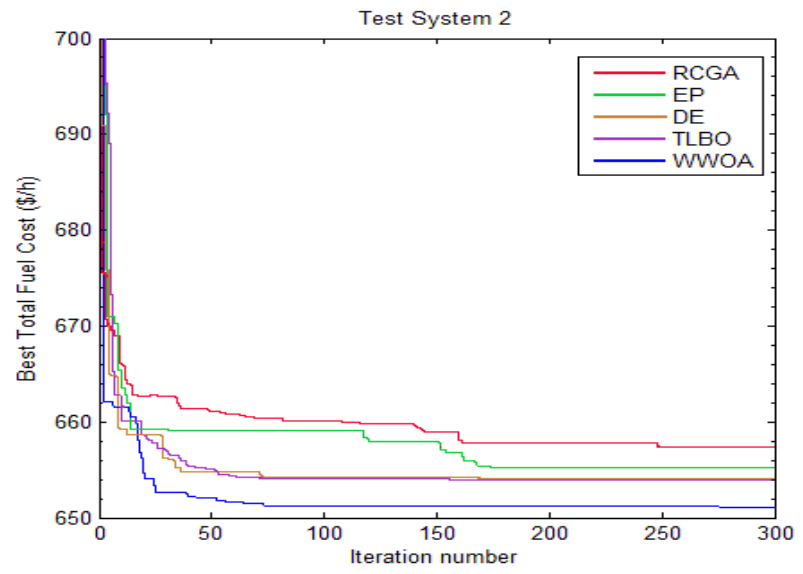

Fig 6: Test System 2 - Cost convergence characteristics comparison 
Table 3: Simulation results comparison for Test System 3 (4 area 40 units with valve point loading)

\begin{tabular}{|c|c|c|c|c|c|c|}
\hline & Units (MW) & RCGA & EP & $\mathrm{DE}$ & TLBO & WWOA \\
\hline \multirow{10}{*}{ 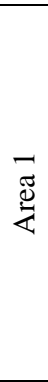 } & $\mathrm{P}_{1,1}$ & 95.7552 & 107.6644 & 111.5448 & 110.8971 & 110.8002 \\
\hline & $\mathrm{P}_{1,2}$ & 88.5828 & 112.0673 & 111.7092 & 112.9550 & 110.8000 \\
\hline & $\mathrm{P} 1_{, 3}$ & 97.6063 & 91.8132 & 98.2429 & 97.4151 & 97.4002 \\
\hline & $\mathrm{P}_{1,4}$ & 126.496 & 175.3171 & 179.8834 & 179.9466 & 179.7332 \\
\hline & $\mathrm{P}_{1,5}$ & 71.0127 & 92.4242 & 95.9500 & 89.4955 & 87.8004 \\
\hline & $\mathrm{P}_{1,6}$ & 116.3866 & 112.5634 & 139.3533 & 139.8937 & 140 \\
\hline & $\mathrm{P}_{1,7}$ & 244.5857 & 257.5370 & 259.3395 & 259.7338 & 259.6000 \\
\hline & $\mathrm{P}_{1,8}$ & 210.6920 & 297.3619 & 285.3569 & 284.6387 & 284.5998 \\
\hline & $\mathrm{P}_{1,9}$ & 236.1685 & 285.2035 & 284.9627 & 284.7414 & 284.5997 \\
\hline & $\mathrm{P}_{1,10}$ & 130.1286 & 134.5862 & 130.2217 & 130.1151 & 130.0001 \\
\hline \multirow{10}{*}{ 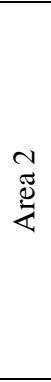 } & $\mathrm{P}_{2,1}$ & 367.4862 & 162.4313 & 243.6005 & 168.8311 & 168.7996 \\
\hline & $\mathrm{P}_{2,2}$ & 297.9501 & 217.8387 & 95.3890 & 168.8214 & 168.8001 \\
\hline & $\mathrm{P}_{2,3}$ & 394.9246 & 125 & 214.5171 & 125.0623 & 214.7599 \\
\hline & $\mathrm{P}_{2,4}$ & 370.3473 & 384.0187 & 394.0808 & 394.2799 & 394.2794 \\
\hline & $\mathrm{P}_{2,5}$ & 455.7123 & 397.6902 & 394.2481 & 394.2529 & 394.2794 \\
\hline & $\mathrm{P}_{2,6}$ & 393.9673 & 407.4993 & 394.4360 & 484.0429 & 394.2794 \\
\hline & $\mathrm{P}_{2,7}$ & 424.1994 & 500 & 489.9552 & 489.2840 & 489.2799 \\
\hline & $\mathrm{P}_{2,8}$ & 484.5498 & 480.8874 & 488.8885 & 489.2703 & 489.2794 \\
\hline & $\mathrm{P}_{2,9}$ & 528.4148 & 524.8487 & 511.4713 & 511.3347 & 511.2794 \\
\hline & $\mathrm{P}_{2,10}$ & 511.4125 & 499.7857 & 511.4125 & 511.4548 & 511.2794 \\
\hline \multirow{10}{*}{ 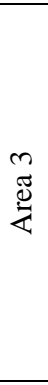 } & $\mathrm{P}_{3,1}$ & 525.4497 & 523.4522 & 523.2896 & 523.2816 & 523.2796 \\
\hline & $\mathrm{P}_{3,2}$ & 510.7391 & 526.5051 & 523.2950 & 523.4321 & 523.2794 \\
\hline & $P_{3,3}$ & 533.6399 & 537.3675 & 523.4129 & 523.3770 & 523.2794 \\
\hline & $\mathrm{P}_{3,4}$ & 518.1120 & 525.7752 & 523.4073 & 523.5974 & 523.2794 \\
\hline & $\mathrm{P}_{3,5}$ & 538.1994 & 531.2092 & 523.7703 & 523.5493 & 523.2794 \\
\hline & $P_{3,6}$ & 527.4775 & 513.5659 & 523.5424 & 523.2773 & 523.2794 \\
\hline & $\mathrm{P}_{3,7}$ & 24.4133 & 11.3612 & 10.1621 & 10.1442 & 10.0001 \\
\hline & $\mathrm{P}_{3,8}$ & 28.9856 & 10 & 10.1326 & 10.0248 & 10.0000 \\
\hline & $\mathrm{P}_{3,9}$ & 28.8571 & 10 & 10.6366 & 10.0862 & 10.0001 \\
\hline & $\mathrm{P}_{3,10}$ & 87.9016 & 78.3523 & 88.181 & 88.2354 & 87.8010 \\
\hline \multirow{10}{*}{ 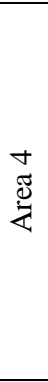 } & $\mathrm{P}_{4,1}$ & 159.7482 & 162.4482 & 161.2220 & 189.9190 & 167.8486 \\
\hline & $\mathrm{P}_{4,2}$ & 153.6255 & 166.3508 & 189.5668 & 189.9718 & 190 \\
\hline & $\mathrm{P}_{4,3}$ & 160.4706 & 190 & 189.9240 & 190 & 190 \\
\hline & $\mathrm{P}_{4,4}$ & 169.9359 & 178.4541 & 165.6621 & 164.8927 & 164.7998 \\
\hline & $\mathrm{P}_{4,5}$ & 168.5220 & 168.0752 & 165.4321 & 165.1343 & 164.8004 \\
\hline & $\mathrm{P}_{4,6}$ & 172.2638 & 174.4529 & 164.9868 & 165.2322 & 164.7997 \\
\hline & $\mathrm{P}_{4,7}$ & 91.2423 & 77.3875 & 109.8137 & 90.2758 & 89.1153 \\
\hline & $\mathrm{P}_{4,8}$ & 86.4778 & 90.1059 & 109.7935 & 109.9813 & 89.1152 \\
\hline & $\mathrm{P}_{4,9}$ & 88.3627 & 109.5654 & 10.1543 & 90.2019 & 89.1141 \\
\hline & $\mathrm{P}_{4,10}$ & 279.2691 & 549.0335 & 459.1140 & 458.9376 & 511.2794 \\
\hline \multirow{6}{*}{ 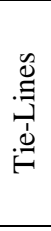 } & $\mathrm{T}_{12}$ & -71.7855 & 200 & 172.0652 & 185.5862 & 189.471 \\
\hline & $T_{31}$ & 161.9336 & 17.5885 & -36.3060 & 23.6686 & 7.1441 \\
\hline & $T_{32}$ & 95.2833 & 200 & 191.1128 & 183.0863 & 188.6132 \\
\hline & $\mathrm{T}_{41}$ & -76.1340 & 90.8733 & 86.8070 & 47.1037 & 71.9935 \\
\hline & $\mathrm{T}_{42}$ & -52.3900 & 100 & 98.8231 & 94.6933 & 85.5997 \\
\hline & $\mathrm{T}_{43}$ & 83.4418 & 100 & 45.0391 & 97.7497 & 88.2794 \\
\hline & Cost $(\$ / h)$ & $1,28,046.50$ & $1,23,591.90$ & $1,21,794.80$ & $1,21,760.50$ & $1,21,592.76$ \\
\hline
\end{tabular}

\subsection{Test System 3}

This system comprises forty generators organized in to 4 areas interconnected with six transmission tie-lines considering the valve-point loading effects. The generator data has been taken from [13]. The total load demand of the system is 10,500 MW. Area 1 includes first ten units and $15 \%$ of the total load demand. Area 2 has second ten generators and $40 \%$ of the total load demand. Area 3 consists of third ten generators and $30 \%$ of the total load demand. Area four includes last ten generators and $15 \%$ of the total load demand. In this system the transmission loss is neglected. The tie-lines interconnecting all the other areas except area 4 has the power flow limit of $200 \mathrm{MW}$, while tie-lines which connects area 4, have the power flow limit set at $100 \mathrm{MW}$. The population size and the maximum iterations are taken as 100 and 500 respectively. The results of WWOA are compared with some of the very recent techniques such as RCGA, EP, DE and TLBO. The comparative test result for this system is given in Table 3. It shows that the proposed algorithm had attained the best total generation cost on par with other recent methods. The comparison of real power generation and the total generation cost have been shown in Fig. 7 and Fig. 8 respectively. The cost convergence characteristics comparison of the test system 3 is shown in Fig. 9. 


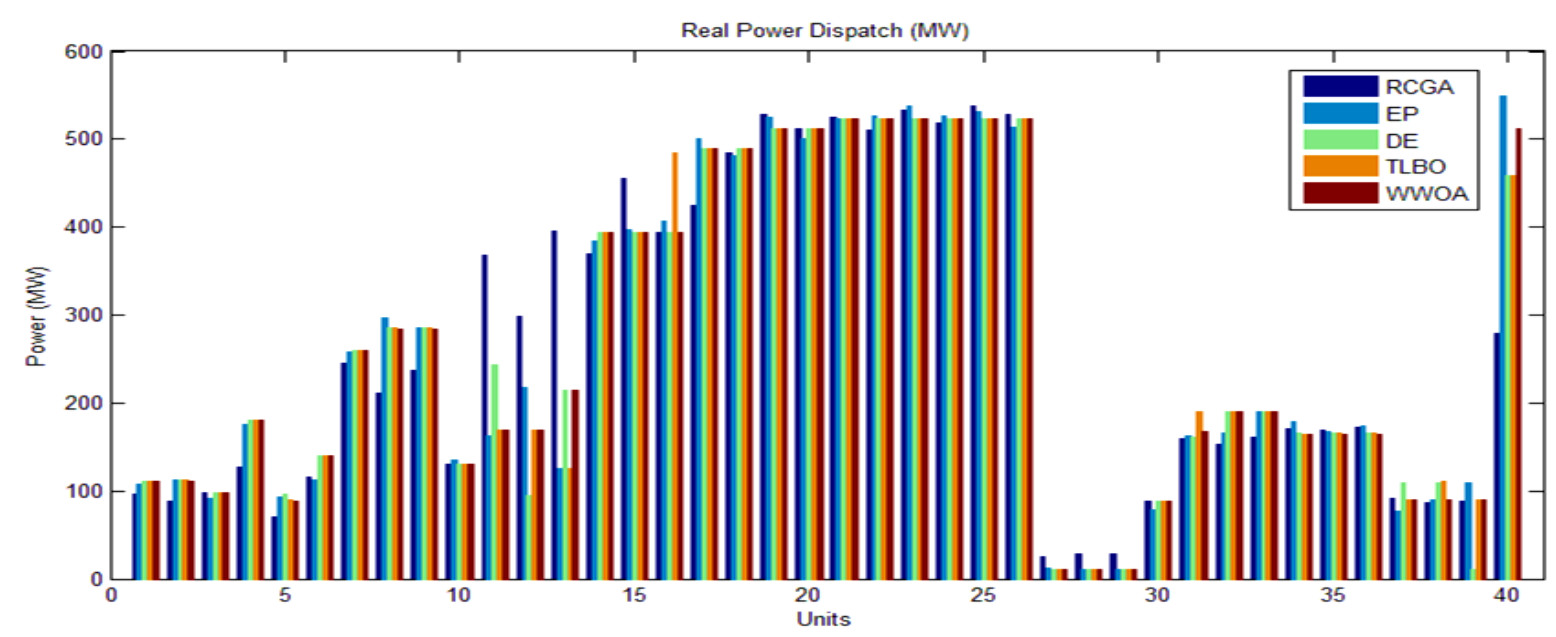

Fig 7: Test System 3 - Power dispatch comparison

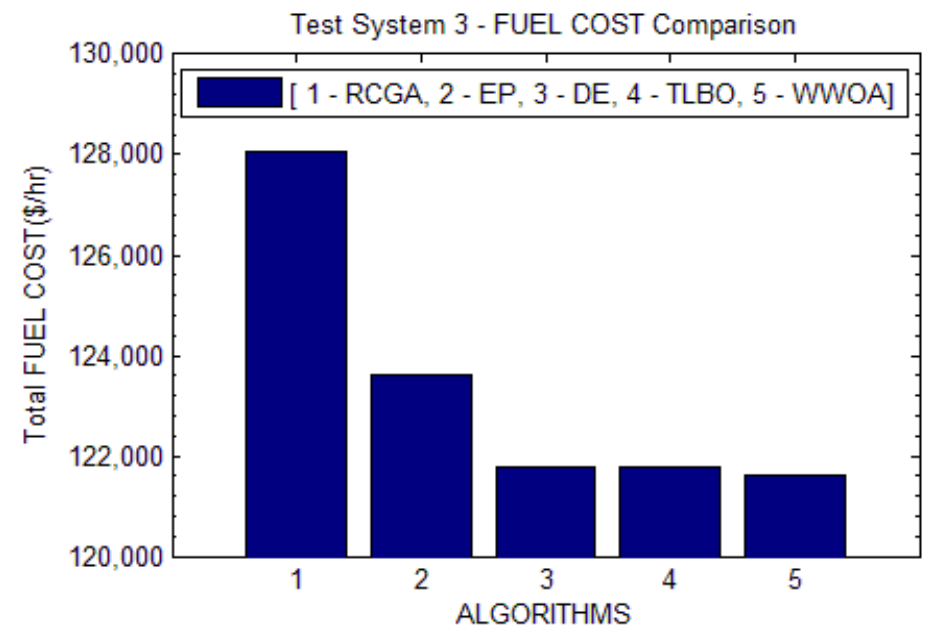

Fig 8: Test System 3 - Fuel cost comparison

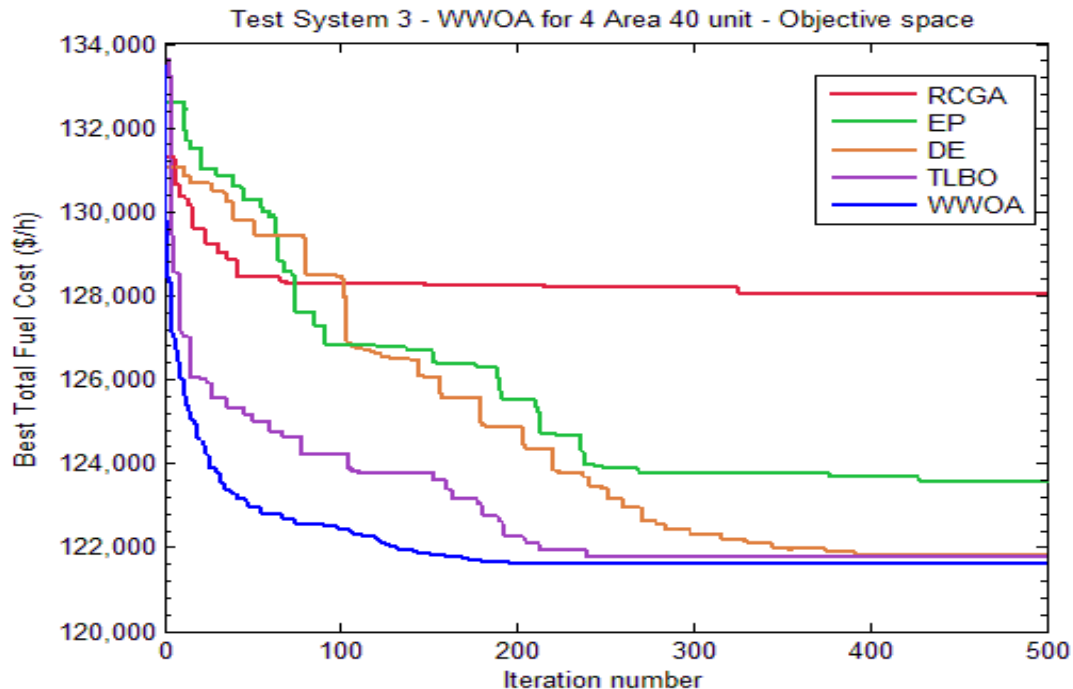

Fig 9: Test System 3 - Cost convergence characteristics comparison 


\section{CONCLUSION}

In this work, Water wave optimization algorithm has been effectively implemented to solve multi-area economic dispatch problems including tie-line constraints; multiple fuel options prohibited operating zones, valve-point loading effects and transmission loss. The tie-line constraints forced no restrictions on the generator cost function as the algorithm has the capability to handle the additional constraints properly. The proposed WWOA method was tested on three test systems and their results have been compared with those of the recently reported literature results such as RCGA, EP, $\mathrm{DE}$ and TLBO. The simulation results show the algorithm's efficient approach in determining the optimal generation schedule without getting trapped in to local optima. The features like Breaking and Refraction support the algorithm in exploitation and exploration capabilities respectively. The advantage of the proposed method is that it requires only few control parameters to control the exploration and exploitation. The global or near global optimum results obtained using the WWOA approach indicates its applicability and validity for solving multi-area economic dispatch problems. The comparison of results shows that the proposed method is capable to produce a better quality solution than the other existing methods recently reported in the literature.

\section{ACKNOWLEDGMENTS}

The authors gratefully acknowledge the support and facilities provided by the authorities of Annamalai University, Annamalainagar, India to carry out this research work.

\section{REFERENCES}

[1] Chowdhury B.H. and Rahman S. 1990 "A review of recent advances in economic dispatch", IEEE Trans. Power Syst., 5 (4), 1248-1259.

[2] Shoults R.R., Chang S.K., Helmick S. and Grady W.M., 1980 "A practical approach to unit commitment, economic dispatch and savings allocation for multiplearea pool operation with import / export constraints", IEEE Trans Power Apparat Syst., 99 (2), 625-635.

[3] Romano R., Quintana V. H., Lopez R and Valadez V., 1981 "Constrained economic dispatch of multi-area systems using the Dantzig-Wolfe decomposition principle", IEEE Trans Power Apparat. Syst., 100 (4), $2127-2137$

[4] Lin C. E., and Chou C. Y., 1991 "Hierarchical economic dispatch for multi-area power systems", Elect. Power Syst. Res., Vol. 10, 415-421.

[5] Tseng C. L., Guan, X., and Svoboda A. J., 1994 "Multi area unit commitment for large scale power systems", IEE Proc. Generat. Transm. Distrib., Vol. 4, 415-421.

[6] Wang C., and Shahidehpour, S. M., 1992 "A decomposition approach to non-linear multi-area generation scheduling with tie line constrains using expert systems", IEEE Trans. Power Syst., Vol. 7, 14091418.

[7] Gaing Z., and Huang H.-S., 2004 "A review of recent advances in economic dispatch", IEEE TENCON Region 10 Conference, 3, 323-326.

[8] Paranjothi S. R., and Anburaja K., 2002 "Optimal power flow using refined genetic algorithm," Elect. Power Compon. Syst., Vol. 30, 1055-1063.

[9] Jeddi, B., Vahidinasab, V., 2014 "A modified harmony search method for environmental / economic load dispatch of real-world power systems", Energy Convers. Manage, Vol. 78, 661-675

[10] Amjady N. and Sharifzadeh H., 2010 "Solution of nonconvex economic dispatch problem considering valve loading effect by a new modified differential evolution algorithm", Int. J. Electr. Power Energy Syst., 32 (8), 893-903.

[11] Basu M. and Chowdhury A., 2013 "Cuckoo search algorithm for economic dispatch", Energy, Vol. 60, 99 108.

[12] Aragon V.S., Esquivel S.C. and Coello C.A., 2015 "An immune algorithm with power redistribution for solving economic dispatch problems", Inf. Sci., Vol. 295, 609 632.

[13] Sinha N., Chakrabarti R. and Chattopadhyay P.K., 2003 "Evolutionary Programming Techniques for Economic Load Dispatch", IEEE Trans. on Evolutionary Computation, 7(1), 83-94.

[14] Secui D.C. 2015 "The chaotic global best artificial bee colony algorithm for the multi-area economic/emission dispatch", Int. J. Energy, Vol. 93, 2518-2545.

[15] Zheng Y. J., 2015 "Water Wave Optimization: A New Nature-Inspired Metaheuristic", Computers \&Operations Research, Vol. 55, 1-11.

[16] Chiang C. L., 2005 "Improved Genetic Algorithm for Power Economic Dispatch of Units with Valve-Point Effects and Multiple Fuels", IEEE Transactions On Power Systems, 20 (4), 1690-1699.

[17] Basu M., 2014 "Teaching-learning based optimization algorithm for multi-area economic dispatch", Energy, Vol. 68, 21-28.

[18] Gaing Z-L., 2003 "Particle Swarm Optimization to Solving the Economic Dispatch Considering the Generator Constraints", IEEE Transactions On Power Systems, 18 (3), 1187-1195.

[19] Streiffert D., 1995 "Multi-area economic dispatch with tie line constraints", IEEE Trans Power Syst., 10 (4), 1946-1951. 